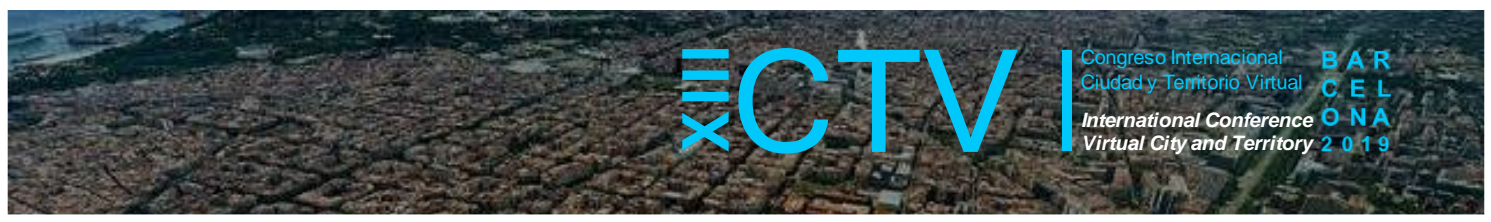

\title{
GENTRIFICACIÓN Y NEGOCIOS INMOBILIARIOS EN MEXICO
}

\author{
Merchand Rojas, Marco Antonio ${ }^{1 *}$
}

Remisión inicial: 2019-04-29; Remisión definitiva: 2019-09-09; Publicación: 2019-12-21

Citación: Merchand, M. A. (2019). Gentrificación y Negocios Inmobiliarios en México. En XIII CTV 2019 Proceedings: XIII International Conference on Virtual City and Territory: "Challenges and paradigms of the contemporary city": UPC, Barcelona, October 2-4, 2019. Barcelona: CPSV, 2019, p. 8504. E-ISSN 2604-6512. DOI http://dx.doi.org/10.5821/ctv.8504

Resumen

El objetivo de esta ponencia consiste en analizar como la reestructuración urbana emprendida por el Estado y los negocios inmobiliarios, revitalizan o rehabilitan áreas o zonas urbanas que forman parte del centro de la ciudad a partir de su valor patrimonial de inmuebles históricos reformados o construidos. Estas zonas urbanas revitalizadas 0 reestructuradas, se pueden llevar acabo, porque se expulsa o despoja a los habitantes oriundos de estas zonas urbanas, lo que conforma una inercia y atmósfera de negocios financieros inmobiliarios que potencializan sus rentas a partir de generar nuevas formas de consumo (compra o renta de departamentos suntuosos y/o generación de consumo conspicuo). A estas, reestructuraciones urbanas emprendidas, se le bautiza como proceso de gentrificación. El objeto epistémico y teórico sobre la significación que cobra el proceso de gentrificación, equivaldría a un proceso de segregación residencial en áreas metropolitanas periféricas, debido a los altos precios de suelo en la zona central rehabilitada y que generan expulsión de población hacia periferias distantes. Así mismo, esta gentrificación se concibe con un rol "pro-empresarial" siendo este rol funcional a los altos márgenes de acumulación privada de renta de suelo y, a un mercado de producción de vivienda nuevo, en suelo central -centros históricos-. A través de estudios de opinión y levantamiento de datos en situ, se confirma que la gentrificación, sería como un proceso que interconecta la liberación, privatización, revitalización y desposesión de gran parte de los espacios más rentables de la ciudad y demuestra los intereses que existen por parte de las elites para controlar la producción de la ciudad. Los datos obtenidos, muestran que las expulsiones de las poblaciones de las áreas por rehabilitar se realizan muchas de las veces con actos de despojo violento sobre sus valores sociales-culturales y/o pisos habitacionales y entonces en esos mismos espacios, ya libres de presión social, se edifican edificios verticales, centros comerciales, restaurantes, galerías que ofrecen funcionalidad a una nueva población de altos ingresos o visitantes turísticos para que recorran y admiren, edificios, calles y barrios renovados con otro imaginario urbano más ad hoc al fetiche mercantilizado, todo esto se lleva a cabo por la sincronía de intereses entre los financieros inmobiliarios y un Estado federal y local que jurídicamente legitima, el despojo. Las conclusiones preliminares fundamentadas en recorridos de campo in situ apuntan a señalar que los procesos de gentrificación, construyen ciudades que se han convertido en escenarios de lucha entre la tendencia globalizante y la revitalización de las identidades locales. Se observa la intensificación de la especialización del espacio urbano en sectores sociales con distintos usos del suelo, globalizados, especializados y competitivos.

\begin{abstract}
The objective of this paper is to analyze how urban restructuring undertaken by the State and real estate businesses revitalize or rehabilitate urban areas or areas that are part of the city center based on their heritage value of historic buildings renovated or built. These revitalized or restructured urban areas can be carried out, because the native inhabitants of these urban areas are expelled or dispossessed, which forms an inertia and atmosphere of real estate financial businesses that potentiate their income from generating new forms of consumption (purchase or rent of sumptuous apartments and / or generation of conspicuous consumption). These, urban restructuring undertaken, are baptized as a gentrification process. The epistemic and theoretical object of the significance of the gentrification process would be equivalent to a process of residential segregation in peripheral metropolitan areas, due to the high prices of land in the rehabilitated central area and generating population expulsion towards distant peripheries. Likewise, this gentrification is conceived with a "pro-business" role, this functional role being to the high margins of private accumulation of land rent and, to a new housing production market, in central land - historical centers. Through opinion studies and data collection on site, it is confirmed that gentrification would be like a process that interconnects the liberation, privatization, revitalization and dispossession of a large part of the most profitable spaces of the city and demonstrates the interests that exist by elites to control the production of the city. The data obtained show that the expulsions of the populations of the areas to be rehabilitated are often carried out with acts of violent dispossession of
\end{abstract}

\footnotetext{
${ }^{1}$ Universidad de Guadalajara, https://orcid.org/0000-0001-8172-7188. * Correo contacto: merchandrojas@yahoo.com.mx
} 


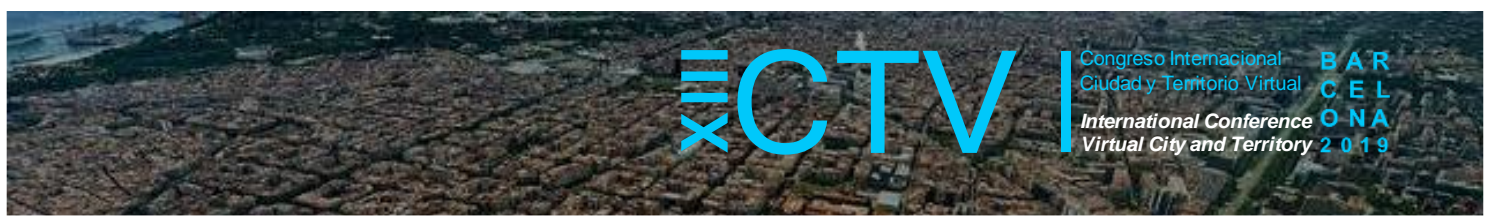

their social-cultural values and / or housing flats and then in those same spaces, already free of social pressure. , vertical buildings, shopping centers, restaurants, galleries are built that offer functionality to a new high-income population or tourist visitors to tour and admire, renovated buildings, streets and neighborhoods with another urban imaginary more ad hoc to the commodized fetish, all this It is carried out by the synchronicity of interests between the real estate financiers and a federal and local state that legally legitimizes the dispossession. Preliminary conclusions based on field recordings in situ aim to point out the processes of gentrification, build cities that have become situations of struggle between the globalizing trend and the revitalization of local identities. Observe the intensification of the specialization of urban space in social sectors with different land uses, globalized, special and competitive.

Palabras claves: Estado; Inmobiliarias; acumulación por desposesión; capitalismo

Key words: State; Real Estate; accumulation by dispossession; capitalism

\section{Introducción}

El concepto articulador que enlaza la trama argumentativa de este escrito, es el de la acumulación por despojo y/o desposesión que cobra fuerza ideológica a partir del modelo neoliberal y que representa, si no la única forma, si la más importante actualmente para sostener o incrementar la acumulación de capital en las ciudades (David Harvey, 2014). E rasgo económico-político que definiría, dicha acumulación por despojo, es que su instrumentación para llevarse a cabo, necesita obligatoriamente que el Estado y los dueños de capital (financiero-inmobiliario) tengan el interés común "contubernio" de que los espacios receptores (construcción de oficinas, centros comerciales, zonas habitacionales, etc.) sirvan para que el capital incremente su capital, este incremento acumulativo de capital, se instrumenta a través de procesos de gentrificación, densificación o construcción de zonas habitacionales en las periferias.

Esta acumulación por despojo en la edificación de ciudades, se aplica como un principio unificador (por igual) en todas las economías del orbe; sean estas desarrolladas o en desarrollo. Uno de los rasgos que ha cobrado importancia en el tipo de acumulación por despojo se inicia con el apoyo irrestricto del Estado para salvaguardar los intereses del capital financiero-inmobiliario (por ejemplo, en la crisis financiera inmobiliaria en Estados Unidos y España, etc.).

Sin embargo, las condiciones en que el capital financiero inmobiliario se impone en cada espacio urbano difieren en sus métodos y maneras de reproducirse; no obstante, su carácter intrínseco de enajenar y/o externalizar lo internalizado en beneficio de pocos, se ha generalizado en la economía global (se aplica por igual en todas las ciudades).

La acumulación por despojo, no puede implementarse, sin el apoyo irrestricto del Estado, éste ha sido un actor central para privatizar y mercantilizar el espacio urbano. Siendo el Estado, empleador de la violencia y hacedor de la legalidad, es evidente que todo proceso económico que implique manejo de recursos económicos y/o activos financieros pasa por su tamiz para cubrir el despojo jurídicamente, pues hay que recordar que el Estado es un poder de clase que se expresa en flexibilizar las leyes (desregulación) para que las distintas denominaciones del capital se adueñen de ejercer el derecho a la ciudad de forma exclusiva.

La perversa lógica inmobiliaria, a través de la exclusión de clases pobres del centro de la ciudad, es el quid, fundamental del conflicto. La desproporción de fuerzas entre los que controlan el mercado inmobiliario y las clases pobres, obliga a los actores implicados a 


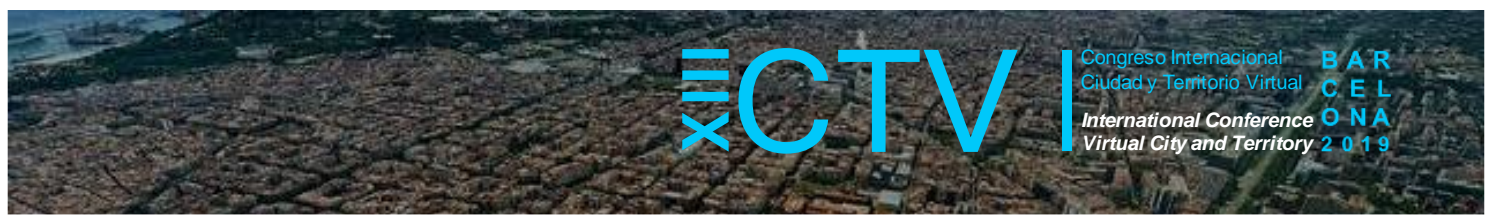

métodos pocos convencionales: abandono, resistencia vecinal, criminalización y terrorismo de Estado (Arch. Daily 2015).

Como bien lo explica, (Hernández, G 2015) la fabricación de ciudades obedece a lógicas políticas, técnicas, económicas y simbólicas que son inherentes a la planificación urbana. La administración pública, instancia encargada de la planificación urbana, presenta en la actualidad una tendencia a enfatizar un interés particular por la imbricación entre las lógicas económicas y simbólicas. Sobre la lógica económica, se ha escrito considerablemente en el ámbito de la planificación. Sobre la lógica simbólica, podría afirmarse que configura sistemas de ideas y valores que sirven para sustentar, promover o justificar las operaciones de urbanismo, haciendo ver su producto como ideal, necesario o deseable para la ciudad.

Esta lógica simbólica, cargada de nuevos productos, se expresa, específicamente en "nuevos productos inmobiliarios, cuya presencia modifica partes emblemáticas del paisaje urbano, se destaca cierta infraestructura inmobiliaria para el esparcimiento y la cultura y, en especial, los edificios de gran altura, que tienden a ser utilizados como emblemas de paisaje urbano globalizado y como "marca" que permite individualizar a cada ciudad en la competencia interurbana" (Mattos, C 2016/47).

En síntesis, se analizará, el concepto de gentrificación, cómo es una estrategia de política urbana para consolidar capitales inmobiliarios en razón de socializar pérdidas y privatizar ganancias y así renovar zonas urbanas. Siendo así, este documento está divido en dos apartados.

- Gentrificación inmobiliaria y empresarialismo.

- La gentrificación financiera inmobiliaria en México.

\section{Gentrificación inmobiliaria y empresarialismo}

La gentrificación forma parte de los procesos de reestructuración urbana cíclica a partir del interés de inversionistas inmobiliarios y financieros en invertir en antiguos barrios urbanos apoyados a través de la gestión público-privada para obtener los beneficios que reproduzcan su capital financiero inmmobiliario. Esto ha permitido a los grandes inversionistas privados la captura de las rentas urbanas potenciales y ha implicado la sustitución directa e indirecta de población residente con nuevos segmentos de clase social, así como nuevas formas de consumo y apropiación de la ciudad.

Los gobiernos neoliberales, presentan el fenómeno de gentrificación con un ascetismo, donde el conflicto social y sus propias contradicciones que genera, están ausentes y/o simplemente son inexistentes, sustituyendo el concepto de gentrificación por conceptos, cómo el de conservación, mejoramiento, reconquista, remodelación, rehabilitación, etc. Como, también lo explica, Uriel Martinez: "Cuando se habla de gentrificación, inevitablemente se hace referencia a un fenómeno de clase, a pesar de ello, la fuerte connotación política que tiene el concepto, ha hecho que se opte por la utilización de términos que han enmascarado las principales consecuencias del proceso. Así es frecuente escuchar en los discursos dominantes ejercidos por las instituciones de gobierno, las palabras "recuperación", "rescate" o "revitalización" para legitimar las intervenciones urbanas orientadas por el interés capitalista que tienen como principal consecuencia el desplazamiento de sectores de población de clase baja por la incorporación de población de clase media-alta" (Martinez, U 2015/3) 


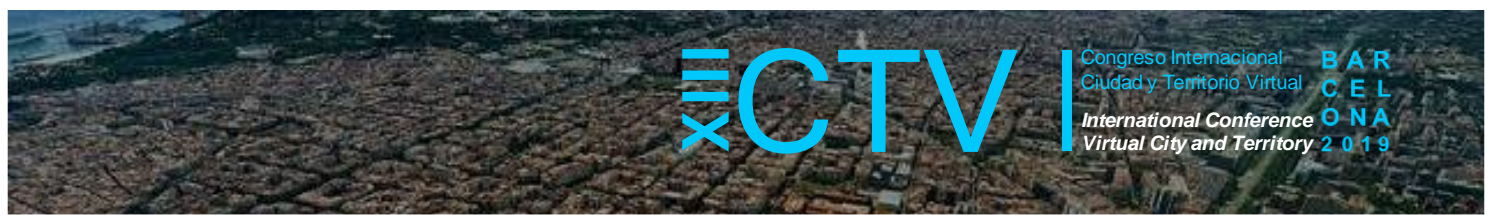

Sin embargo, hay que ubicar con exactitud el significado de gentrificación, a este concepto, hay que asociarle, dos dimensiones para las cuales parecía tener una especial relevancia: 1) la gentrificación liderada por los agentes inmobiliarios, y 2) la interrelación entre gentrificación y las múltiples luchas vecinales. Estas dos dimensiones y/o vertientes que se estiman, serían las apropiadas para evidenciar las consecuencias veladas de las políticas urbanas contemporáneas y así re-politizar los estudios urbanos, desde un horizonte que se relaciona con las reivindicaciones ciudadanas.

También, habría que agregar que al término gentrificación, lo acompaña la expresión explícita, de una violencia de consumo (apropiación de predios) y la violencia engendrada por la lucha de clases. Sin embargo, las verdaderas intenciones de estas violencias que genera este proceso de gentrificación, se ocultan por políticas urbanas asociadas y/o veladas a los poderes inmobiliarios financieros. En otras palabras, el proceso de gentrificar, arrastra el poder de expresar la dominación de los poderosos (agentes urbanos) detrás de la renovación urbana: el Estado, el capital inmobiliario y los bancos entran a concertaciones a través de operadores de gobierno y agentes urbanos.

Los estudios sobre de la gentrificación y sus repercusiones en América Latina, atraviesan desde los primeros trabajos sobre renovación urbana, hechos por Castells $(1974,1978)$, y otros representantes de la sociología urbana francesa; las teorías de la ciudad revanchista, la recuperación de áreas para clases acomodadas (Smith y Williams, 1986; Smith, 1987 y 2002 ) y el regreso al inner-city (Ley, 1996); o estudios sobre la planeación y los proyectos de renovación urbana, que ejemplifican la gentrificación dirigida por el Estado y la inversión privada (Rojas, 2004; Lungo y Smolka, 2007; Cuenya, Novais y Vainer, 2012) así como la renovación de centros históricos en Latinoamérica (Carrión, 2004; Carrión y Hanley, 2005).

En el caso del concepto de gentrificación a los procesos urbanos en el América latina, este fenómeno tiene sus particularidades y rasgos muy específicos en cada uno de los países, de ahí que Janoschka, M y Sequera, J (2014) hable de des-centrar los debates acerca de la gentrificación, incluyendo lo específico de los contextos latinoamericanos. Luego entonces, la adaptación del término gentrificación, no puede ser lineal, sino que es necesario tener en cuenta las especificidades locales, regionales y nacionales que determinan cómo se desarrollan los procesos de gentrificación en lugares con condiciones sociales, políticas y económicas que varían marcadamente respecto de los países anglosajones, europeos y latinoamericanos (Casgrain, A y Janoschka, M 2013).

Nos explica, Janoschka y Sequera que una de las consecuencias claves de las transformaciones sociales y políticas que afectaron a las ciudades de América Latina en las últimas dos décadas, ha consistido en la proliferación de políticas públicas que tienen el objetivo (explícito o implícito) de desplazar a las clases populares de las áreas centrales. El proceso es acompañado por una inversión inmobiliaria masiva que materializa la reconquista de los centros urbanos para las clases pudientes.

Las generalidades que caracterizan al proceso urbanizados gentrificador es el despliegue de tres aspectos claves: (i) el rol decisivo que las administraciones públicas juegan en los procesos de gentrificación en América Latina, especialmente en relación a los efectos violentos que ocurren a partir de la creación de nuevos mercados inmobiliarios; (ii) la violencia simbólica que es aplicada por la re-apropiación del patrimonio arquitectónico y cultural; (iii) la violencia 


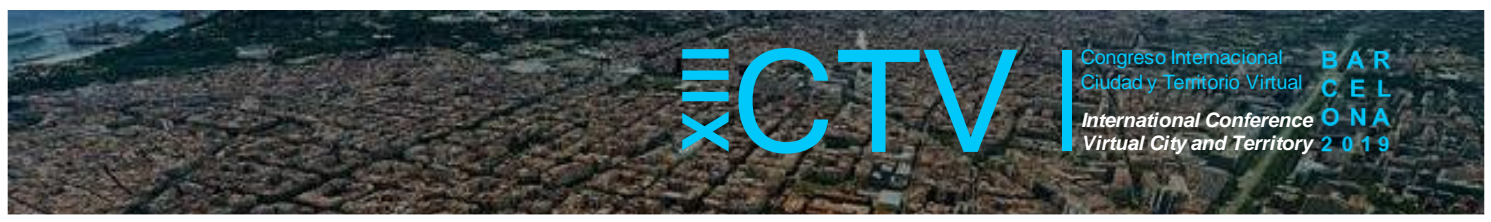

que se aplica en la formalización de unas economías y unas ciudades producidas y vividas en gran medida bajo la informalidad.

Bien lo acota, Christof Parnreiter (2011) que nos dice, no hay que olvidar a Saskia Sassen, que desde hace tiempo advirtió en su libro "The Global City" (Sassen, 2001), que la formación de la ciudad global está relacionada con modificaciones en la economía inmobiliaria. Primero, el surgimiento de funciones de la ciudad global aumenta la demanda por oficinas de alta calidad, porque las empresas dedicadas a los servicios al productor requieren de una infraestructura digna para poder captar deberes de control y administración en la economía global. La consecuencia de este aumento de demanda, es un boom de construcción, enfocado a ciertos barrios -por lo general en los centros- y ciertos sectores del mercado -los inmuebles oficina de primera clase-. Por ende, desde los años 1980 "la rápida construcción de un complejo de oficinas de gran altura, uno tras otro" caracteriza a la transformación física de ciudades globales. Además, se está formando un mercado inmobiliario transfronterizo cuyas zonas centrales se localiza en las ciudades globales (Sassen, S 2001).

Acorde a lo acotado por Christof Parnreiter (2011), la Ciudad de México, despliega las características de una ciudad global, debido a que las mismas transformaciones de los mercados inmobiliarios urbanos, se motiva esencialmente por la "fuerza motriz" de procesos de la formación de la ciudad global. Por un lado, la presencia cada vez más grande de empresas globales (principalmente, pero no sólo, en el sector de los servicios al productor) aumenta la demanda de inmuebles de oficinas de alta calidad, que no existían antes en el volumen demandado en las ciudades de la semiperiferia de la economía global.

Por otro lado, liberalizaciones amplias de mercados financieros acompañados por una crisis de inversiones productivas, desembocaron en que más y más capital buscará posibilidades de inversión en mercados inmobiliarios florecientes en todo el mundo. Christof Parnreiter (2011), insiste que referente a la Ciudad de México, ésta es el resultado de un boom de construcción, financiado más por inversiones extranjeras, principalmente en el sector de inmuebles de oficinas de máxima calidad. Estas inversiones foráneas que canalizan sus ideas en construcción de inmuebles de oficinas para empresas corporativas, constituye un precedente para realizar una transformación y remodelación de la estructura arquitectónica de la ciudad. Un ejemplo clásico, es la construcción del nuevo CBD (Central Business District) en Santa Fe, y otro, es la actual remodelación y recuperación del Paseo de la Reforma, que comenzó con la construcción de la Torre Mayor.

"La Torre Mayor no solamente es un espacio de la ciudad global, sino también un espacio transnacionalizado que "aunque se inserta en el espacio físico del territorio nacional", puede tener poco que ver con el contexto circundante. Hay que recalcar que, en 2013, el mismo, Paul Reichmann de Fibra Uno y el Fideicomiso Farca/Salame, construyen la Torre Diana, a dos calles de Torre Mayor. La Torre Diana, es un edificio de oficinas Clase A+ de 33 pisos situado en el Corredor de Reforma, en la zona central de negocios de la ciudad de México. Torre Diana comenzó a construirse en abril de 2013 (El proyecto se construiría sobre 6.243 metros cuadrados de terreno propiedad del Fideicomiso) y los inquilinos ancla/principales podrán comenzar sus mejoras a mediados de 2015. Torre Diana es comparable a los mejores diseños hechos en Nueva York y Londres, incluso la Torre Mayor de la Ciudad de México, es actualmente, el rascacielos más alto del país y es también construido por la familia Reichmann" (Christof Parnreiter 2011/32). 


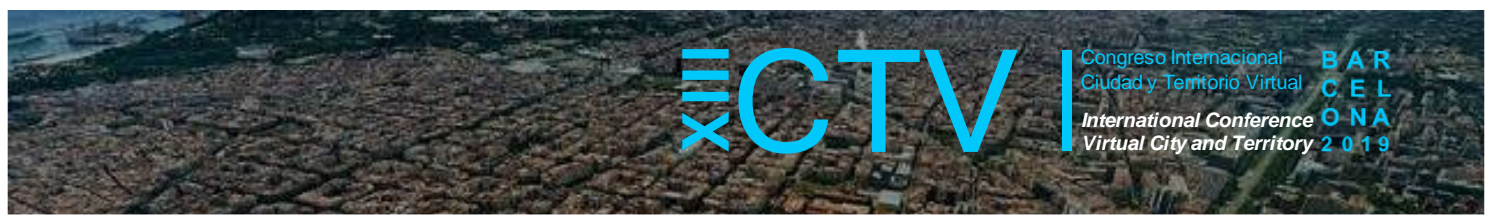

En general, las grandes empresas transnacionales, han aprovechado su presencia en el centro histórico para desplegar una amplia oferta de productos y servicios. No podemos, olvidar que es a través de la gestión pública encargada de roles de (competitividad urbana y de city marketing), el de atraer capitales inmobiliarios que intensifiquen la mercantilización de la transformación urbana de México.

La creciente importancia de capitales inmobiliarios mundiales, acompañados por una gestión estatal empresarial, han potencializado la importancia de los negocios inmobiliarios sobre todo de la Ciudad de México, que se está transformando en una metrópoli nacional hacia una "bisagra" entre la economía mexicana y la economía global y, como tal, es un lugar importante para la producción y gestión de la globalización de México (Parnreiter, Ch 2002).

Sin olvidar, que el que garantiza, condiciones estables y seguras para los capitales inmobiliarios, es el propio Estado como un agente central que abona un rol crucial de proveer una visión del futuro sólida, en un periodo de transformación.

El Estado sigue jugando un rol protagónico en la escena global, aunque sus funciones y estructura hayan cambiado significativamente en las últimas décadas. El enfoque de gestión pública sustentado por criterios de neutralidad y subsidiaridad, ha contribuido a consolidar condiciones mucho más favorables para los negocios inmobiliarios. Se propicia un nuevo paradigma empresarial" en manos del sector público, el empresarialismo urbano expresa una nueva modalidad de gobernanza, que han adoptado autoridades locales de tendencias políticas diversas (Harvey, 1989, 2001; Borja y Castells, 1997; Rodríguez et al., 2001; OECD, 2007; Mattos, 2009).

Se admite que el empresarialismo, es una forma de regulación política y social que se refleja y se acompaña por procesos de reestructuración en las economías capitalistas en las últimas décadas. En respuesta a la crisis del desarrollo fordista y de su Estado social keynesiano (desindustrialización, desempleo y austeridad presupuestaria fiscal), en muchas metrópolis del mundo, se asistió a una ampliación del rol de los gobiernos locales, junto con una redefinición en las prioridades de las políticas urbanas. Estas políticas pasaron a asignar un rol protagónico al capital privado en el desarrollo urbano. La atracción de inversiones privadas se convirtió en un objetivo clave para contrarrestar la declinación económica de las ciudades y aumentar la base de sus recursos fiscales.

En la práctica, estas estrategias de empresarialismo urbano, se han presentado de manera combinada, articulándose con constantes innovaciones de producción, de consumo, culturales, en el estilo de vida, en los productos y servicios e incluso en formas institucionales y políticas para poder operar en un contexto de fuerte competencia interurbana.

\section{La gentrificación financiera inmobiliaria en México}

La ciudad neoliberal que se mencionó con anterioridad, se materializa en la ciudad de México (Distrito Federal), gracias a las iniciativas conjuntas y/o alianzas entre el gobierno del Distrito Federal y la iniciativa privada local que generará un espacio atractivo para las inversiones inmobiliarias, llevando a cabo procesos de gentrificación excluyente. 


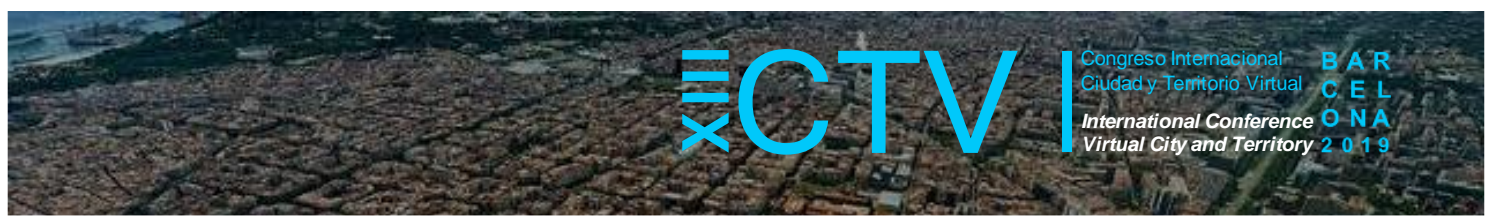

Para ejemplificar, el concepto de gentrificación que se ha llevado a cabo en el valle de México, se escogió tres áreas que han sido sometidas a procesos de gentrificación, estas son: el Centro Histórico de la ciudad de México, Santa Fe y el nuevo Polanco. Las dos primeras gestiones ocurrieron simultáneamente, posteriores a 1987 y el tercer ejemplo, en el año 2008 (Olivera, P 2014).

La gestión privada neoliberal emprendida en contubernio por el Estado y los grupos empresariales, han favorecido al grupo Carso (propiedad del Ing. Carlos Slim -el hombre más rico del mundo- el cual constituye un grupo financiero con negocios en numerosos segmentos de la industria, comercio y servicios, empresas de telecomunicaciones, bancarias, comercio departamental, de alimentos, construcción e inmobiliarias. El titular vitalicio -Carlos Slim- del Grupo Carso (Telmex, América Móvil, Grupo Financiero Inbursa, Compañía Minera Frisco, etcétera) y accionista mayoritario del diario The New York Times.

Hay que recordar que los cambios en el centro de la ciudad de México, se inscriben en la serie de mega proyectos de los que también forman parte Santa Fe, Polanco y Paseo de la Reforma. Los instrumentos que posibilitaron estas transformaciones se remontan a la creación de las Zonas Espaciales de Desarrollo Concentrado (Zedec's) -surgidas en el marco de la negociación del Tratado de Libre Comercio- expedidas al término del sexenio de Salinas de Gortari, con las cuales se modificaba el tipo y la intensidad del uso de suelo. Como resultado de estas nuevas políticas públicas, se construyeron importantes inmuebles como la Torre Mayor en Reforma, hoteles de gran turismo (cinco estrellas) como el Hotel Sheraton del Centro Histórico y proyectos inmobiliarios para clases altas, como Puerta Alameda.

En el año 2000, el jefe de gobierno del Distrito Federal (Andrés Manuel López Obrador) publicó el bando 2, un brevísimo documento que generó expectativas para el mercado inmobiliario. Este ordenamiento atrajo masivamente inversiones inmobiliarias privadas a las delegaciones centrales, el flujo de capital en el mercado inmobiliario revaloró los espacios urbanos de las cuatro delegaciones centrales y prácticamente de todo el Distrito Federal. Elevándose la rentabilidad en la ciudad de México, hasta alcanzar el tercer sitio de América Latina en términos de inversiones inmobiliarias (Cushman and Wakefiel Real Estate, Winning in Growth cities 2012. http:www.cushwake.com $)^{2}$.

Esta rentabilidad aludida, se logró gracias a que el Gobierno del Distrito Federal realizó acciones de "limpieza", cabe destacar el caso; del Programa Parcial de Desarrollo Urbano del Centro Alameda (Zona Verde) que dentro de sus acciones estratégicas consistieron en restituir la estructura simbólica de la zona a través de espacio público, fisonomía urbana, sitios patrimoniales, generar vivienda nueva y reciclada, mezcladas con otros usos. Las calles del Centro Histórico, experimentaron el desplazamiento y supuesta reubicación de los comerciantes ambulantes, además de desencadenar un proceso de salida de las clases pobres a través de desalojos obligados.

De acuerdo al reportaje realizado por Luis Gómez (2006/SP): Las inmobiliarias del Centro Histórico de Lomelí-Collet a través de los empresarios (Carlos Slim y Manuel Arango), llevaron a cabo desalojos de los edificios catalogados con adeudos en el pago de predial o estaban intestados, de tal forma que "presionaron" a los propietarios de los predios a venderlos a

${ }^{2}$ Citado por Olivera, P (2014). 


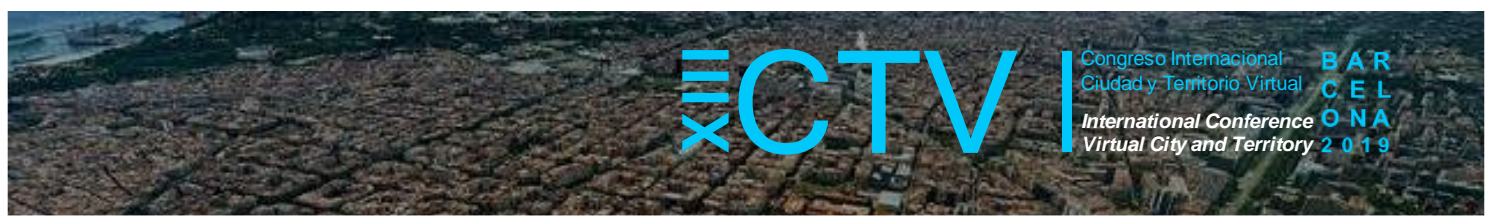

precios irrisorios, muchas veces utilizando "prácticas gansteriles". Estos atropellos y expulsiones violentas se denunciaron a través de la Unión de Vecinos y Comerciantes del Polígono Centro Histórico.

No obstante, los reclamos que se han registrado por el proceso de gentrificación, la inversión privada desde del 2003 hasta 2013, es de 3,500 millones de pesos en los perímetros A y B de la zona centro, por parte del Gobierno del Distrito Federal (GDF) la inversión fue de 500 millones pesos, siete veces menos que la privada; esto es, las inversiones privadas tuvieron una magnitud mucho mayor a las públicas y reafirma, la acumulación privada de capital apunta como mayoritaria. Esto ocasionó, que se revalorizara aceleradamente la zona centro, hasta a aumentar el precio de los predios en un $500 \%$; estas circunstancias favorables, provoca que la zona centro, se ha apropiada por las inmobiliarias del empresario Carlos Slim, quien posee 79 predios en la zona. El propio grupo Carso, ha expresado que, en el Centro Histórico de la Ciudad de México, la plusvalía de la zona se ha triplicado en 10 años por la presencia de hoteles, cafés, clubes, comercios (Grupo Carso 2013/112). Para Olivera y Delgadillo, destacan dos procesos centrales de la gestión urbana gentrificadora en la Ciudad de México:

"Por una parte las formas de desalojo cuyos antecedentes encontramos en el Centro Histórico, dividido entre la ciudad de los palacetes, con abundantes y suntuosas edificaciones alrededor de la plaza central y calles comerciales hacia el poniente, y bordeándola por el oriente de norte a sur, la ciudad de los tugurios, con los barrios populares de La Merced, Guerrero, Morelos, Tepito, Peralvillo y Tlatelolco, todos ellos en la delegación central Cuauhtémoc. En estos barrios surgieron en las décadas de 1970 y 1980 los movimientos urbanos populares que compartieron experiencias de lucha contra los planes de regeneración urbana con una "avanzada capacidad" para formular propuestas propias para la defensa social de sus barrios", ya que hubo procesos de desalojo intensos, en varios momentos" (Olivera y Delgadillo, 2013/9).

Desde 1990, la gestión urbana se orientó hacia la "ciudad competitiva", movilizando inversiones a través de negocios involucrados con el desarrollo inmobiliario. Cabe aclarar, que esta ciudad competitiva, se logró gracias a las políticas e incentivos que promovieron nuevos enclaves de servicios globales a través de la construcción de megaproyectos con usos mixtos, la edificación de centros comerciales, vivienda residencial y en menor medida social. Por supuesto que estas edificaciones urbanas segregaron o excluyeron a la población de bajos ingresos, quien ha tenido que emigrar a periferias urbanas distantes 0 a áreas rurales, sin servicios, ni infraestructuras.

Cómo se ha analizado, los procesos de la gentrificación llevados a cabo, han sido, Santa Fe, el Centro Histórico y norte de Polanco. Cabe explicar que: este caso de Santa Fe, bien lo remarca y señala, Margarita Pérez: "Así, Santa Fe expresa el discurso de la globalización en una sección de la ciudad. Sus complejos arquitectónicos expresan lo que a nivel social e individual se busca transmitir: el poder del libre mercado y de la competencia. Al igual que una persona busca proyectar la imagen del éxito a través de su imagen externa y en su interior busca incansablemente el confort y una mejor calidad de vida, los complejos arquitectónicos de la zona buscan proyectar una fachada novedosa e interiores cálidos y seguros. Pero, además, la individualidad y el poder que refleja una fachada monumental también define el papel de los actores en el espacio, recordándoles a través del poder simbólico que ejerce la arquitectura 


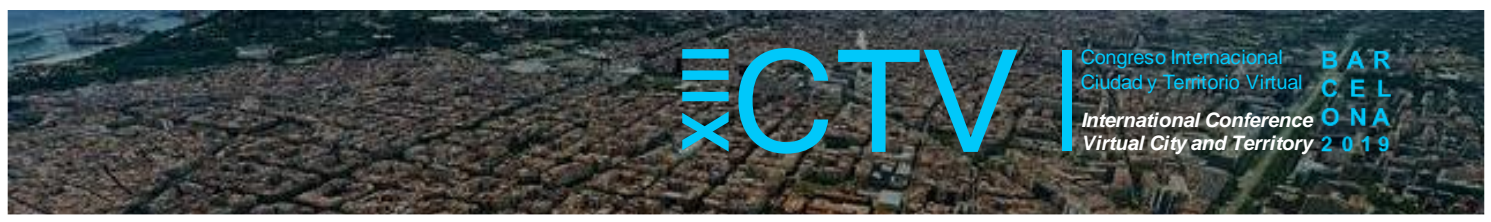

cuál es su posición en el abanico de la sociedad, preservando e intensificando con ello los patrones de desigualdad social" (Pérez, M 2009/44).

Esta cita ilustra a la perfección a la conclusión que llega Margarita Pérez en su artículo, sobre el significado de Santa Fe, ésta nos comenta, que con Santa Fe se fortalece, así el proyecto político neoliberal que busca privilegiar una apertura económica; al crear una imagen y proveer la infraestructura necesaria para articularse a nivel global; por otro, se consolida una dinámica que privatiza la seguridad y contradictoriamente, la sociabiliza.

En el caso del Centro histórico, el interés en la mercantilización de su patrimonio arquitectónico, se inicia en la década de 1990 y se emplean los eslóganes de rescate, revitalización, rehabilitación, aun llamados de recuperación del Centro Histórico para denominar programas, con una carga simbólica que busca introducir la transformación necesaria e inminente, haciéndola atractiva para el sector privado, las finanzas y legitimidad del gobierno.

Por otro lado, en las dos últimas décadas tres colonias históricas colindantes con el Centro Histórico (Roma, Condesa e Hipódromo), se han convertido en un referente de la ciudad, por el incremento de oferta cultural, gastronómica, comercial y de entretenimiento, y por la oferta residencial dirigida al consumo de las clases medias y medias-altas. Estas tendencias, han sido promovidas 0 reforzadas por las políticas públicas recientes. Aquí hay que destacar a la Colonia Hipódromo que se localiza en la Delegación Cuauhtémoc, dentro de la denominada Ciudad Central de la Ciudad de México -conformada por las delegaciones Cuauhtémoc, Miguel Hidalgo, Benito Juárez y Venustiano Carranza-. En los inicios de los años noventa, la colonia paso por un proceso de redensificación habitacional y de reactivación comercial que la convirtió en un espacio privilegiado para el mercado inmobiliario de lujo; los costos de suelo se incrementaron en menos de diez años, casi el 200\% (Gómez, S 2014).

Cómo se analizó, con anterioridad, el concepto de empresarialismo urbano se aplica al caso de estudio de la Colonia Condesa, barrio localizado en el área central de la Ciudad de México. Aquí, la gestión urbana del gobierno de la Ciudad de México y de la Delegación Cuauhtémoc (jurisdicción administrativa a la que pertenece dicha colonia) ha contribuido a impulsar diversas transformaciones urbanas, las cuales consisten principalmente en: incremento de establecimientos comerciales a partir de cambios de uso de suelo y de cambios de giro mercantil, y crecimiento de oferta inmobiliaria de uso habitacional dirigida para un sector de ingresos medios y altos. Dichas transformaciones, han sido identificadas previamente con el concepto de gentrificación (Salinas, L 2014).

La revitalización de los barrios históricos en las colonias Roma, Condesa e Hipódromo Condesa constituye un proceso de reactivación comercial de la zona configurada y/o mapeada por el negocio inmobiliario, con claros matices del imaginario urbano. Por último, respecto al nuevo Polanco ${ }^{3}$ se desarrollaron varios megaproyectos, en lo que fue la antigua zona industrial en el poniente de la delegación Miguel Hidalgo, donde convergían todo tipo de fábricas: de

\footnotetext{
3 "El acelerado crecimiento inmobiliario en lo que se conoce como el Nuevo Polanco o el Manhathan mexicano, que abarca alrededor de 12 colonias, sobre todo Granada y Ampliación Granada, no avanzó a la par de la infraestructura urbana, lo que provocó un deterioro en la red hidráulica y en el drenaje, así como un colapso vial en las principales arterias, lo que obligó desde mediados del año pasado a la Secretaría de Desarrollo Urbano y Vivienda (Seduvi) a cancelar la emisión de nuevos permisos de construcción (González, R y Gómez, L 2015/10).
} 


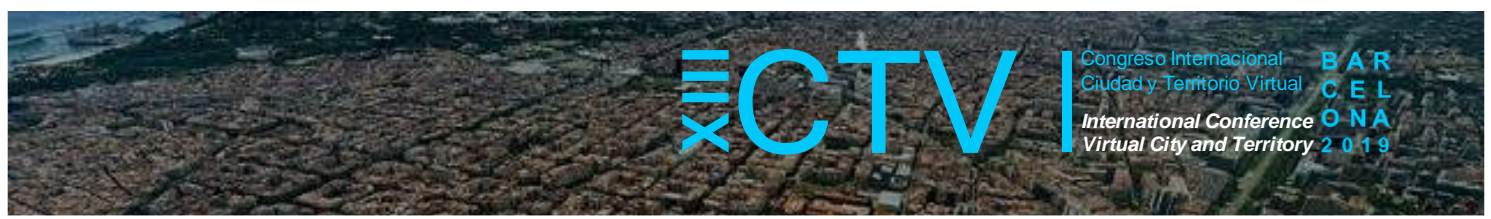

telas, vidrio, jabón, muebles y plásticos. En los años recientes, esta zona se transformó en una exclusiva área de rascacielos para oficinas, departamentos, plazas comerciales y museos. El norte de Polanco, ubicado en la Delegación Miguel Hidalgo, se asientan denominados "desarrollos urbanos integrales" con usos mixtos de vivienda, servicios corporativos, recreativos, banca, restaurantes, comercio, entre ellos, en 2005 se inició el megaproyecto inmobiliario "Plaza Antara, de Promotora Los Atrios y Walton St. Capital" (en la colonia Granada), en 2008 se edifica, Plaza Carso ${ }^{4}$

En 2011,se construyen residencias Polárea, promovido por el grupo corporativo español Lar, en 2012 se edifican Parques Polanco ${ }^{5}$ (en la Colonia Granada), en 2008 se desarrollan La Quadra y Grand Polanco (en la colonia Irrigación) ${ }^{6}$, City Towers (en la colonia Ampliación Granada). El impulso a la "ciudad competitiva", los negocios y el desarrollo inmobiliario abarcan el espectro de políticas e incentivos para el desarrollo de nuevos enclaves de servicios globales, lo que implica la construcción de megaproyectos con usos mixtos, incluyendo de vivienda para clases medias y altas (video: S/A).

La "recuperación" de barrios y centros históricos, la reconversión de la ciudad industrial por la modernización del capital flexible de enclaves de tiempo libre y negocios para usufructo del patrimonio histórico y espacios culturales; define una estrategia excluyente, profundiza la ciudad desigual.

\section{Conclusiones}

Como se ha reflexionado, se aprecia que existe una relación estrecha entre el interés de los Estados Federales o locales en contubernio y comparsa con los intereses de los agentes inmobiliarios (agencias de servicio, hipotecarias, constructoras, consultoras, etc.) de viabilizar proyectos urbanos muy necesarios para la propia dinámica urbana de cualquier ciudad, pero con costos sociales muy graves para el que fue despojado de su lugar de origen. Si bien la regeneración o renovación urbana son deseables, la caracteriza singular de una ejecución inmobiliaria, es que ésta, se aplica con un sesgo de apropiación privada excluyente y generador de pobreza.

Respecto al concepto de gentrificación y su aplicación, éste muestra un carácter dual, para muchos tiene una faceta positiva, ya que mejora el entorno (negocios comerciales -cafeterías, restaurantes, galerías, etc.-.); no obstante, también hay que mostrar su lado negativo, se expulsa a sus habitantes originarios, ya que no pudieron o no los dejaron encontrar una forma de hacer escuchar su derecho a la vivienda (anulación del derecho a la Ciudad). Otros, por fortuna, han encontrado formas asociativas a través de organizaciones populares de vivienda en defensa de su hogar, que luchan por no ser desalojados por los capitales inmobiliarios y el

\footnotetext{
4 "Se encuentra el Museo Soumaya, el Museo Jumex, el Teatro Cervantes, un centro comercial con las tiendas del grupo Carso, hotel y entretenimiento, torres corporativas y de vivienda de 22 niveles con departamentos desde 121 hasta 207 metros cuadrados, cuyos precios oscilan entre 375.000 y 585.000 dólares. Hay que destacar que la Plaza Carso es un complejo de usos mixtos con: oficinas, vivienda, comercio, entretenimiento y cultura. La 1a. etapa, abarcó una superficie construida de 560,000 m2. Las etapas subsecuentes tendrán una superficie construida de 300,000 m2" (Video S/A).

${ }^{5}$ Departamentos en altura 20 niveles de 56 a $186 \mathrm{~m} 2$ con precios entre 185.000 y 558.000 dólares, en predio de $150.000 \mathrm{~m} 2$ (Polarea nuevo Polanco, grupo Lar 2013)

${ }^{6}$ Departamentos en 385.00 dólares (Guía de Inmuebles, septiembre 2013/SP).
} 


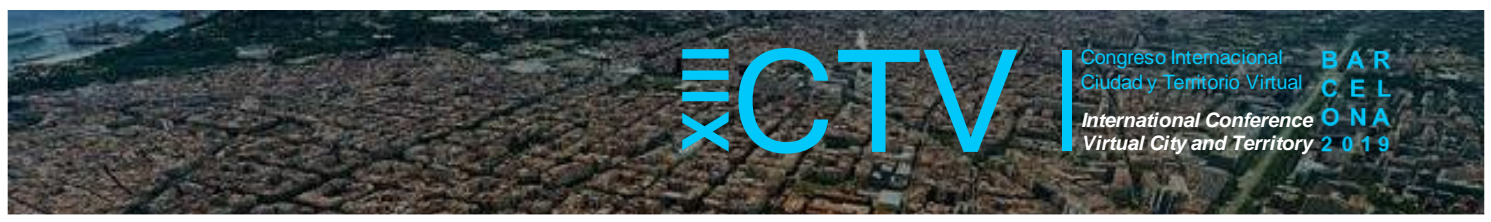

Estado que procuran ambos, lograr por todos medios legales o no legales, el despojarlos de su arraigo de vida, económica, cultural y social.

Por fortuna, ya se están gestando movimientos sociales como forma de contrarrestar la práctica acumulativa de despojo a través del acto especulativo inmobiliario, como el derecho que tenemos todos de contar con vivienda digna y de gozar los espacios públicos que le pertenecen a la ciudadanía en su conjunto. Incluso, proliferan organizaciones como la de No más condominios de la Asamblea del Pueblo de Tetelpa Unido (Aptu) que representan a las barrancas del poniente (Delegación Álvaro Obregón) de la ciudad: defienden la reserva ambiental y manifiestan poner en alto la depredación urbana (Ramírez, B 2016).

\section{Bibliografía}

Arch. Daily. (2015). Video: ficción inmobiliaria (o 16 películas cruzadas por conflictos urbanos). Ecumenopolis "Ficción inmobiliaria" http://www.archdaily.mx/mx/760479/video-ficcioninmobiliaria-0-16-peliculas-cruzadas-por-conflictos-urbanos

Borja, J y Castells, M. (1997). Local y global, La gestión de las ciudades en la era global. Madrid: Taurus. Corporación Antiguo Puerto Madero S.A. Memoria y Estados Contables al 31 de diciembre de 2009 presentados en forma comparativa. Recuperado de: www.puertomadero.com

Carrión, F. (2004). "La división temática de los centros históricos en América Latina" en Martínez, M. E. (ed.), El centro histórico: objeto de estudio e intervención. Bogotá: Editorial Pontificia Universidad Javeriana. http://contested-cities.net/working-papers/wp-content/uploads /sites/8/2014/10/WPCC-14023 Cabrera Proyectodelpaseodelr\%C3\%ADoSanFrancisco.pdf

Carrión, F y Hanley, L. (2005). Regeneración y revitalización urbana en las Américas: hacia un estado estable. Quito, FLACSO, Sede Ecuador. Recuperado de http://www.flacsoandes.edu.ec/libros/17329-opac

Carso. (2013). Revitalización del Centro Histórico. Recuperado de http://www.realestatemarket.com.mx/articulos/infraestructura-y-construccion/11301-como-avefenix-revitalizacion-del-centro-historico-de-la-ciudad-de-mexico

Casgrain, A y Janoschka, M. (2013). Gentrificación y resistencia en las ciudades latinoamericanas. El ejemplo de Santiago de Chile Andamios. Revista de Investigación Social, vol. 10, núm. 22. Recuperado de http://www.redalyc.org/pdf/628/62828837002.pdf

Castells, M. (1974). "Planificación urbana y movimientos sociales: El caso de la Renovación urbana de París". En C. Beringuier, M. Castells (Ed.), Urbanismo y práctica política (págs. 127160). Barcelona: Los Libros de la Frontera.

Castells, M. (1978). La cuestión urbana. México: Siglo XXI.

Cuenya, B y Corral, M. (2011). Empresarialismo, economía del suelo y grandes proyectos urbanos: el modelo de Puerto Madero en Buenos Aires. EURE, v.37, n.111. Recuperado de http://www.scielo.cl/scielo.php?pid=S0250-71612011000200002\&script=sci arttext 


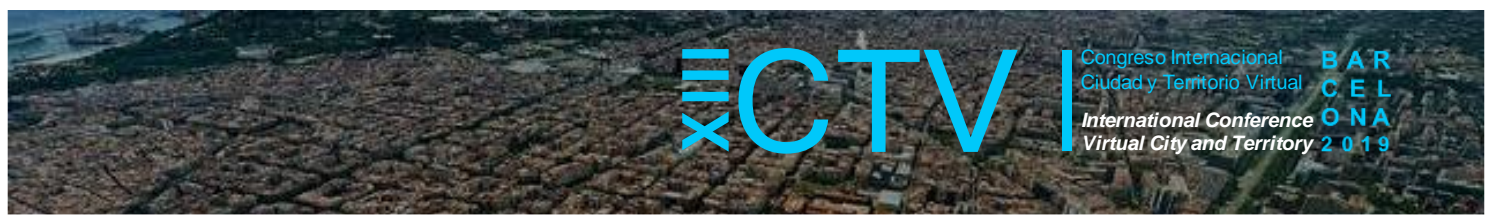

Gómez, L. (2006). Acusan vecinos a Slim y Arango de acaparar inmuebles en el Centro. La jornada. http://www.jornada.unam.mx/2006/05/24/index.php?section=capital\&article=045n1 cap

Gómez, S. (2014). Vivir en el hipódromo. Discursos y motivaciones para habitantes de la ciudad central. Recuperado de http://contested-cities.net/working-papers/wp-content/uploads/ sites/8/2014/10/WPCC-14024 G\%C3\%B3mez Vivirenlahip\%C3\%B3dromo.pdf

González, R y Gómez, L. (2015). Auge inmobiliario colapsa servicios e infraestructura en nuevo Polanco. La Jornada. http://www.jornada.unam.mx/2015/07/19/capital/026n1cap

Guía de Inmuebles. (2013). Recuperado de http://www.guiadinmuebles.com/?gclid=CIWQ4rWgsgCFQmnaQodAAcOPQ

Grupo Carso. (2013). Revitalización del Centro Histórico. Recuperado de http://www.carso.com.mx/ES/Paginas/grupo carso.aspx

Harvey, D. (2014). Diecisiete contradicciones y el fin del capitalismo. 1. ${ }^{a}$ ed. Quito: Editorial IAEN (Instituto de Altos Estudios Nacionales del Ecuador), 2014296 p. Juan Mari Madariaga (Traductor). Recuperado de http://www.cpalsocial.org/documentos/73.pdf

Hernández, G. (2015). Imagen e ideología en el gobierno de la ciudad. Los casos de Montpellier (Francia) y Pereira (Colombia). CUADERNO URBANO. Espacio, cultura, sociedad, vol. 19, núm. 19. Recuperado de http://www.redalyc.org/pdf/3692/369242871004.pdf

Janoschka, M y Sequera, J. (2014). Procesos de gentrificación y desplazamiento en América Latina, una perspectiva comparativista. En Desafíos metropolitanos. Un diálogo entre Europa y América Latina, Juan José Michelini. Editorial Catarata. Madrid. Recuperado http://contestedcities.net/wp-content/uploads/2014/07/2014CC Janoschka Sequera Desplazamiento AL.pdf

Janoschka, M; Sequera, J y Salinas, L. (2014). Gentrificación en España y América Latina. Un diálogo crítico. Rev. geogr. Norte Gd. no.58 Santiago set. 2014. Recuperado de http://www.scielo.cl/scielo.php?pid=S0718-34022014000200002\&script=sci arttext

Ley, D. (1996). The New Middle Class and the Remarking of the Central City. Nueva York: Oxford University Press Inc.

Martinez, U. 2015). Proceso de gentrificación y desplazamiento en el espacio público del centro histórico de la ciudad de México. Recuperado de http://contested-cities.net/workingpapers/2015/proceso-de-gentrificacion-y-desplazamiento-en-el-espacio-publico-del-centrohistorico-de-la-ciudad-de-mexico/

Mattos, C. (2016). "Financiarización, valorización inmobiliaria del capital y mercantilización de la metamorfosis urbana", en Sociologías, Porto Alegre, año 18, no 42, mai/ago. Recuperado de http://www.seer.ufrgs.br/index.php/sociologias/article/viewFile/62169/38345

Mattos, C. (2009). Modernización capitalista, Metamorfosis Urbana y Competitividad en América Latina. Ponencia presentada en Seminario Internacional La Investigación Urbana: Perspectivas y Desafíos, Lima, Perú. Recuperado de www.uarm.edu,pe/Docs/investigacion/.../competitividad mattos.pdf 


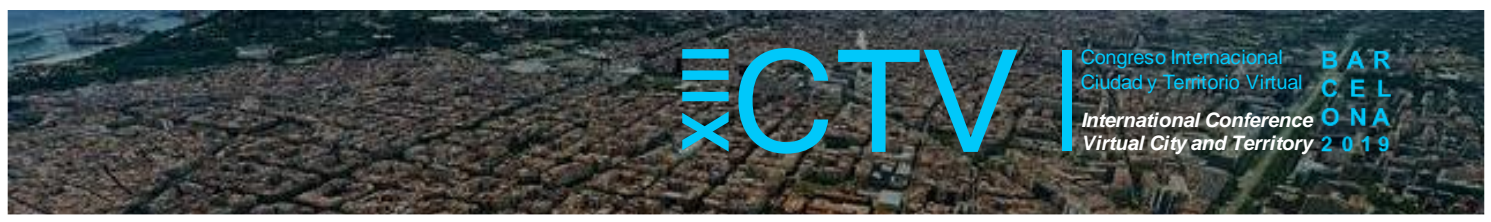

Marx, K. (2004 [1867]). El Capital. México, DF: Ed. Siglo XXI.

OECD Territorial Reviews. (2007). Competitive Cities: A New Entrepreneurial Paradigm in Spatial Development. Recuperado de www.oecd.org/bookshop

Olivera, P y Delgadillo, V (2013). Políticas empresarialistas en los procesos de gentrificación en la Ciudad de México. Revista de Geografía Norte Grande, 58. Recuperado de http://www.redalyc.org/articulo.oa?id=30031739007

Parnreiter, Ch. (2002). Ciudad de México: el camino hacia una ciudad global. Eure Santiago v. 28 n.85. Recuperado de http://www.redalyc.org/articulo.oa?id=19608506

Parnreiter, Ch. (2011). Formación de la ciudad global, economía inmobiliaria y transnacionalización de espacios urbanos. El caso de Ciudad de México. vol 37, no 111. Recuperado de EURE. http://www.scielo.cl/pdf/eure/v37n111/art01.pdf

Pérez, M. (2013). Discurso y materialidad de los procesos constructivos en la Ciudad de México.Alteridades vol.23 no.46 México jul./dic. http://www.scielo.org.mx/scielo.php?pid=S0188 $\underline{-70172013000200002 \& \text { script }=\text { sci arttext }}$

Ramírez, B. (2016). En Álvaro Obregón no cesan los permisos para los megadesarrollos. La Jornada. Recuperado de http://www.jornada.unam.mx/2016/05/11/capital/027n1cap

Rodríguez, A.; Moulaert, F. y Swyngedow, E. (2001). Nuevas políticas urbanas para la revitalización de las ciudades en Europa. Ciudad y Territorio, Estudios territoriales, XXXIII No. 129, Madrid, pp. 409-424. Recuperado de https://dialnet.unirioja.es/servlet/articulo?codigo=257012

Rojas, E. (2004). Volver al centro: la recuperación de áreas urbanas centrales. New York: Banco Interamericano de Desarrollo. Recuperado de https://publications.iadb.org/bitstream/handle/11319/202/Volver\%20al\%20centro.pdf?sequence=1

Salinas, L. (2014). Empresarialismo y transformación urbana. El caso de la ciudad de México. Revista Andaluza de ciencias sociales, Anduli No 13.

Sassen, S. (2001). The Global City: Introducing a concept. Recuperado de http://www.saskiasassen.com/pdfs/publications/the-global-city-brown.pdf

Smith, N. (2002). "New Globalism, New Urbanism: Gentrification as Global Urban Strategy". Antipode. Vol. 34, pp. 427-450. http://www.readcube.com/articles/10.1111\%2F14678330.00249?r3 referer=wol\&tracking action=preview click\&show checkout=1\&purchase refer rer=onlinelibrary. wiley.com\&purchase site license=LICENSE DENIED

Video. (S/A). Torres parques. https://www.youtube.com/watch?v=4dlnJHQZWUs 